\title{
Features of the Use of the Internet by Russian Teenagers: The Regional Aspect
}

\author{
Valentina Kamenskaya*, Leonid Tomanov, Elena Tatianina
}

\author{
Bunin Yelets State University, Institute of Psychology and Pedagogy, Yelets, 399770, Kommunarov Street, 28.1, \\ Russia \\ *Corresponding author: Kamenskaya-v@mail.ru
}

\begin{abstract}
In the last two decades, adolescent behaviour has significantly modified by new factors in the form of information technologies embedded in the education and leisure. There is knowledge that the worse of socio-economic conditions of life determine the increase of gaming activity and communication in social networks of teens. The assumption of our study is that different living conditions in metropolis and industrial city in central Russia determinate the teenagers' actions changes in Internet. The paper used a questionnaire to assess the preferences of gaming and internet activities by students of schools in Moscow and Lipetsk of Russia. Methodical features of the questionnaire in the form of the need to select a single choose from a set of possible answers to the questions determine the specific distribution of teenagers with different kinds of internet activity compared to teenagers in other country. The survey of 144 students of schools in Moscow and Lipetsk online showed both similarities in the use of video games and time on social networks with the well-known features of the younger generation of other countries and the specific features of Russian schoolchildren. Most teenagers of Russia used social media communications compared to gaming, with a sufficient degree of competence, higher in the industrial city, Lipetsk, than Moscow. The time of total interaction with gadgets roughly corresponds to the results of cited works in the sample of teenagers of Lipetsk in Moscow this value is higher. Thus, we have proved the impact of regional conditions on adolescent behaviour in cyberspace with Lipetsk teens' normative characteristic in corresponding Moscow students.
\end{abstract}

Keywords: Russian regions, Teenagers, Internet preferences, Gaming, social media, Internet skills.

\section{INTRODUCTION}

Changing socio-economic and informational environments have a significant impact on the cognitive and social development of young people in Russia, as in all countries. In the last two decades, adolescent behaviour has significantly modified by new environmental factors in the form of digital information technologies embedded in the education, population health and leisure [1]. Teenagers and young people spend much of their time on social media and video games at the expense of physical and social development [2]. In 2013-2015, statistics showed the high involvement of people in many countries in video games using desktop computers, phones and consoles. Video games in their spare time were occupied, according to the estimations of leading American think tanks, 60 to $72 \%$ of children and adolescents [1].

Studies of adolescent behavior in cyberspace show an increase in the use of the Internet gaming during the deterioration of living conditions [3,4]. It is possible that influence of city environments can change the craving for activity in cyberspace. At the same time, there is knowledge about the increasing immersion in virtual communication on social networks in the last years $[5,6]$. Experts have determined the maximum time of interaction in cyberspace, the excess of which creates the risk of internet-additive. As the socioeconomic conditions of the environment worsened, the duration of gaming activity and communication in social networks has increased significantly, which is of concern to parents and specialists of the education and health system in Russia too [2.6]. The assumption of our study is that different living conditions of metropolis and industrial city in central Russia determinate the teenagers' actions changes in Internet. This idea was check in two Russian cities: the metropolis and the capital of the country, Moscow, and the large industrial city, Lipetsk. Moscow is characterize by a high population density, a large number of contacts in transport, shops and other social objects, long time moving to work and study. Lipetsk has more comfort conditions for adults and children. Due to these differences in the life environment of teenagers in Moscow and Lipetsk may be the causes of the different 
behavior forms in cyberspace, we expected, as a way of protecting against situational stress.

\section{METHODOLOGY}

Our study focuses on finding answers to these problems. The aim of the work was to study the internet preferences of 14-15 year olds in 2019-2020 in two Russian cities: Moscow and Lipetsk. The survey involved 146 8th and 9th graders (90 boys and 56 girls) 50 people lived in Moscow, 96 - in Lipetsk. Participants of the survey were interviewed online using the questionnaire "Digital Preferences of Modern Adolescents" by Kamenskaya V.G [7]. The list includes 11 questions on topics related to the use of different kinds of activities on the Internet using various technological devises, with temporary spending on leisure in cyberspace. The peculiarity of the questionnaire is that the participants of the online survey put in a situation of making one choose from a set of possible answers in all questions. Thus, the percentage of answers to each question should leave $100 \%$. The evaluation of the results consisted of assessing the percentage of participants who chose certain response options in the questionnaire. Statistical processing of the results carried out using SPSS-15.0 programs.

\section{KEY RESULTS}

The materials of our survey are partly the same as the facts previously obtained. The high importance of social networks for students of 8th and 9th grades in both Moscow and Lipetsk was study. On fig. 1 the participants of the experiment are responding to the presence of social media accounts. Only $4 \%$ in Lipetsk and $6 \%$ in Moscow do not own accounts, which shows the high value of social media users in Russia in 20192020 (Lipetsk - 96\%, Moscow - 94\%).

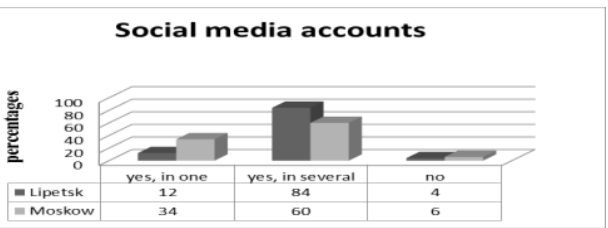

Figure 1 Percentage of active users of social networks in moscow and lipetsk.

It can be noted that the maximum percentage of schoolchildren have profiles not in one network, but in several, the total share of active participants in interaction in social networks is more than $95 \%$, which, indeed, exceeds the percentage of users of social networks in 2018-2019 in Russia [2]. The creating of the permanent platform, blog, on social networks with its own theme and visitors is requiring a certain professional skill and is available to a significantly smaller number of students (Fig. 2)

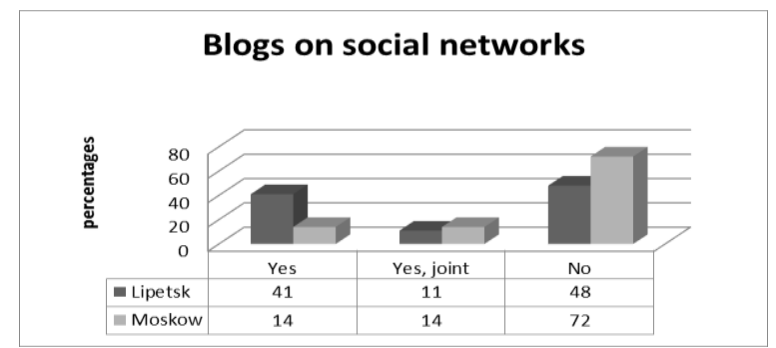

Figure 2 Creating blogs by students in moscow and lipetsk.

Interestingly, such competences was more by students of mass schools Lipetsk, rather than Moscow. During this years, the increase in leisure interaction with gadgets in gaming is approximately in line with the performance of the work [3;4], only in the sample of teenagers Lipetsk, $28 \%$ of whom spend time with gadgets four hours or more. A large percentage (46\%) Moscow teenagers has signs of over-fascination with internet, which exceeds the total number of overinvolved students in the virtual world of other countries. The prevalence of over-attracted internet activity in Moscow compared to Lipetsk reflects the regional characteristics of environment conditions. There is more complex life in Moscow affect teenagers to the fullest, which forced most of them to go into the virtual world.

The need to select a single answer to the questions of survey is the reason of a specific distribution of a sample of teenagers who prefer concrete forms of interaction with gadgets (Fig. 3). Histograms of Fig.3 show a higher percentage of social media users compared to the rest kind activities, which is, however, significantly lower than simple survey on cyber preferences. It is noteworthy that Russian teenagers play much less video games, if you compare $20 \%$ of Lipetsk players and $88 \%$ of young people in Hong Kong for example [3]. It is impossible rule out the impact of the methods of obtaining statistics of gamers.

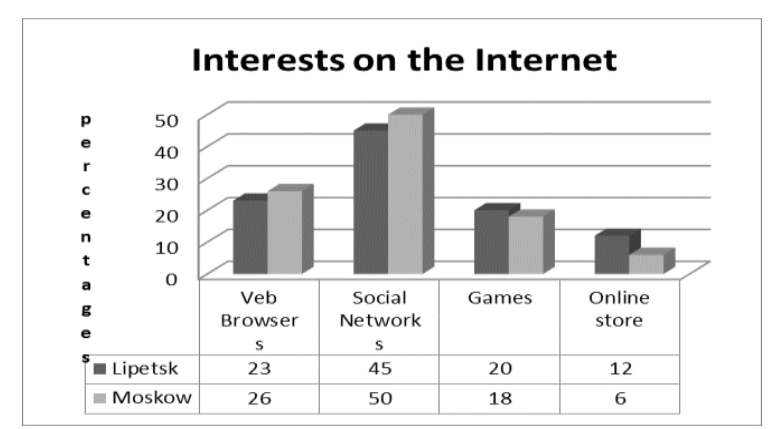

Figure 3 Distribution of the number of consumers of different forms of internet services in teenagers of moscow and lipetsk 
The differences in the use of information technology by teenagers in Moscow and Lipetsk statistically assessed using the non-parametric criterion of Pearson's consent (hi-square). The results of statistical processing given in the table 1 .

Table 1. Results of statistical analysis of the teenagers' behavior on Moscow and Lipetsk in the Internet.

\begin{tabular}{|l|l|l|l|}
\hline & $\begin{array}{l}\text { Value } \\
\text { of the } \\
\text { Pearson }\end{array}$ & df & $\begin{array}{l}\text { Asymtotic } \\
\text { Significance } \\
\text { (two-tailed) }\end{array}$ \\
\hline Issues questionnaire & & & \\
\hline $\begin{array}{l}\text { 1.Time spent with } \\
\text { gadgets }\end{array}$ & 6,583 & 2 &, 037 \\
\hline $\begin{array}{l}\text { 2.Availability Social } \\
\text { Media }\end{array}$ & 10,077 & 1 &, 002 \\
\hline 3.Social Media Blog & 18,947 & 2 &, 000 \\
\hline $\begin{array}{l}\text { 4. Priority Interests } \\
\text { on the Internet }\end{array}$ & 4,827 & 3 &, 185 \\
\hline
\end{tabular}

The results of this analysis show both similarities and reliable differences in responses of the proposed questionnaire. Teenagers of Moscow and Lipetsk have similar preferences in the use of leisure facilities equally prefer to spend their free time in social networks compared to other leisure activities, gaming for example. At the same time, the results reveal reliable differences in behavior in the cyberspace of students in Moscow and Lipetsk. First, the majority of teenagers in Moscow, compared to their peers from Lipetsk, spends four hours or more on the Internet. Secondly, Lipetsk students use time on social networks more diversely, as their significantly higher percentage has several accounts in different social networks. Thirdly, most of Lipetsk's teenagers organize and manage information of blog, which is due to good communication competences in cyberspace.

\section{CONCLUSION}

A survey of Russian adolescents to study their information preferences yielded the following results: 1.Teenagers, regardless of socio-economic conditions of development in Moscow or Lipetsk, preferred virtual communication on social networks. 2. Regional differences are show in the quality and diversity of virtual communication on the Internet: most of Lipetsk's teenagers had blogs and accounts in different social networks.3.Teenagers in Moscow in more numbers showed super fascination with virtual communication than teenagers Lipetsk they spent four hours or more on social networks. 4. The playful activity of Lipetsk teenagers had similar features with the well-known characteristics of game activity of young people in other countries.

For the first time, we have found that in Russian schoolchildren used the Internet and gadgets as a way to reduce stress from complex life conditions in metropolis. In Moscow, the largest metropolis not only in Russia, reliably most of the teenagers had signs overthe-top virtual communication on social media, which confirms the assumption of the number rise in adolescents walked away from stress through virtual communication. Thus, we have proved the impact of regional conditions on adolescent behaviour in cyberspace and using gadgets for gaming.

\section{REFERENCES}

[1] G.Soldatova, O. Teslavskaya,. Mod. For. Psych. 6.21-28 (2017)

[2] D.Rudenkin, A. Rudenkina. Juvenis scientia, 1.4348 (2019)

[3] Shimin Zhu, Yanqiong Zhuang, Paul Lee, Jessica Li, Paul Wai-Ching Wong. Preprint JMIR Serious Games on: Dec. 29, (2020)

[4] Center on Media and Child Health. Video Games. (2020)

[5] Mental Health Foundation. Loneliness during coronavirus. (2020)...

[6] https://www.statista.com/statistics/278414/numberof-worldwide-social-network-users

[7] V. Kamenskaya, L. Tomanov, E. Tatianina, "Family and society: psychological and socioeducational aspects of deviant behavior prevention" Conf. mat. Lipetsk. 40-46 (2020) 